\title{
Effect of autoimmune diseases on incidence and survival in subsequent multiple myeloma
}

\author{
Kari Hemminki ${ }^{1,2^{*}}$, Xiangdong Liu ${ }^{2,3}$, Asta Försti ${ }^{1,2}$, Jianguang $\mathrm{Ji}^{2}$, Jan Sundquist ${ }^{2,4}$ and Kristina Sundquist ${ }^{2,4}$
}

\begin{abstract}
Background: Patients with many types of autoimmune diseases (AIDs) are at an increased risk of cancer, which may depend on underlying dysregulation of the immune system or treatment. We systematically analyzed myeloma risk and survival in patients diagnosed with 33 different AIDs.

Methods: Data on patients with AIDs were retrieved from the Swedish Hospital Discharge Register and were linked to myeloma diagnoses from the Cancer Registry. Standardized incidence ratios (SIR) and hazard ratios (HRs) were calculated for subsequent myeloma between 1964 and 2008.

Results: Among patients with the 33 AIDs analyzed, 457 cases of myeloma were diagnosed. The overall SIR for myeloma was 1.12 and the overall HR was 0.92 and non-significant. SIRs for myeloma were significantly increased after ankylosing spondylitis (2.02) and systemic sclerosis (2.63). Only the HR for myeloma after rheumatic fever (5.27) was significantly increased. The SIR for myeloma before age 60 years was 1.45; the SIR for myeloma was only increased in the period 1964-1990 (1.31) and not later (1.04). Only the SIR for myeloma after ankylosing spondylitis was increased in the period 1991-2008 (2.09); the HRs for myeloma were increased after polymyositis/ dermatomyositis (6.44) and rheumatic fever (4.43) but there were only three deaths of myeloma after these AIDs.

Conclusions: The present data showed an increase in myeloma SIR after two AIDs, ankylosing spondylitis and systemic sclerosis, and in HR after rheumatic fever. The overall myeloma risk after any AID was no longer increased in the latter follow-up period of 1991 through 2008.
\end{abstract}

Keywords: Autoimmune disease, Multiple myeloma, Incidence, Survival

\section{Introduction}

Autoimmune (AI) diseases (AIDs) constitute many different diseases with systemic or local manifestations, which jointly affect 5 to $10 \%$ of the population in the developed countries [1]. AIDs are characterized by the activation of $\mathrm{T}$ cells or B cells, or both, in the absence of an ongoing infection. The normal function of these cells is to recognize specific foreign antigens, but they possess a low level of autoreactivity towards own (self or auto) antigens. In AIDs, autoreactivity is increased and symptoms develop [2]. Many cancers are increased in AID patients for reasons that are not known [3-6]. The immunological disturbances in AIDs may be an important

\footnotetext{
*Correspondence: k.hemminki@dkfz.de

'Division of Molecular Genetic Epidemiology, German Cancer Research Center (DKFZ), Im Neuenheimer Feld 580, Heidelberg D-69120, Germany ${ }^{2}$ Center for Primary Health Care Research, Lund University, Malmö 20502 , Sweden

Full list of author information is available at the end of the article
}

mechanism to cancer formation because cancers typically arise in organs with AI manifestations [3-6]. However, treatment with immunosuppressive therapy may also contribute [7]. Many AIDs are treated with nonsteroidal anti-inflammatory drugs and as these are protective against many cancers, they may help to hide carcinogenic effects of AIDs [8].

Multiple myeloma is an incurable malignant disease of clonal plasma cells, which accumulate in the bone marrow and cause clinical sequelae characterized by the production of monoclonal protein, displacement of normal hematopoiesis, bone marrow neovascularization, formation of osteolytic bone lesions, hypercalcemia and renal failure [9]. Myeloma arises from B-cells with somatic hypermutations in the variable region immunoglobin genes [10]. Hypermutations occur in germinal centers and thus myeloma development is thought to be related to post-germinal center immune stimulation. Chronic antigenic stimulation has long been suggested to drive

\section{() Biomed Central}


myeloma development [11]. Already in 1987, a personal history of rheumatic fever and urinary tract infections was associated with myeloma risk [12]. Myeloma risks have also been associated with pernicious anemia and polymyalgia rheumatic in previous Swedish studies $[3,13]$. In US veterans, myeloma risk was associated with polymyositis/dermatomyositis, systemic sclerosis, autoimmune hemolytic anemia, pernicious anemia and ankylosing spondylitis [4]. The data on rheumatoid arthritis has been controversial and data on Crohn disease and sarcoidosis have been negative $[3,14,15]$. Whether AID influences myeloma survival has deserved less attention and the studies on survival after rheumatoid arthritis, Crohn disease, ulcerative colitis and psoriasis have shown no effect [16-18].

In the present study we examined risks of myeloma (standardized incidence ratio, SIR) and survival in myeloma (hazard ratio, HR) systematically in patients, who had been hospitalized for any of 33 AIDs, covering the total Swedish population. As myeloma treatment has changed over the years with improvements in survival, we analyzed also periodic effects [19].

\section{Material and methods}

The research dataset used in the present study is a subset of the national dataset maintained at the Center for Primary Health Care Research, Lund University, Malmö, Sweden, and has been used previously [6]. AID patients were identified from the Swedish Hospital Discharge Register, which contains data on all hospital discharges (dates of hospitalization and diagnoses) for some regions of Sweden since 1964 and for the whole of Sweden since 1986. The International Classification of Diseases codes used have been described previously [20,21]. A total of 33 AIDS were covered. However, for 12 AIDs (Addison's disease, amyotrophic lateral sclerosis, autoimmune hemolytic anemia, celiac disease, chorea minor, type 1 diabetes, discoid lupus, localized scleroderma, lupoid hepatitis, polyarteritis nodosa, primary biliary cirrhosis and Reiter's disease) there were fewer than four cases of myeloma. These diseases were not significantly associated with myeloma (as assessed by SIR and HR) and data are not shown for them. The linkages were performed by means of the individual national identification number that is assigned to each person in Sweden for their lifetime. This number was replaced by a serial number for each person in order to provide anonymity.

SIRs were calculated as the ratio of observed to expected number of myelomas. Expected numbers were calculated for anyone not hospitalized for AID. The expected numbers were calculated as age (5-year groups), sex, period (5-year groups), region and socioeconomic status-specific standard incidence rates. Additional adjustments were made for hospitalization for obesity using codes $\mathrm{ICD} 7=287.00,287.09 ; \mathrm{ICD} 8=277.99 ; \mathrm{ICD} 9=$ 278A; ICD-10= E65-E68. A total of 30,020 individuals had been hospitalized for obesity. Similar adjustments were made for smoking using hospitalization for chronic obstructive pulmonary disease as a surrogate with 260,243 individuals affected (codes: ICD7 $=500-502$; ICD8 = 490-493; ICD9 =490-496; ICD-10= J40-J49), and alcohol using alcoholisms as surrogate (codes: ICD9 $=303$; ICD-10=F10.1-F10.9) with 181,862 individuals affected. Confidence intervals $(95 \% \mathrm{CI})$ were calculated assuming a Poisson distribution.

Person-years of follow-up were calculated from date of discharge with the first main diagnosis of AID until death, emigration, or closing date, December 31, 2008. The Cox regression analyses were used to estimate HRs, which could be interpreted as mortality rate ratio. Adjustments were done as above. The analyses were for cause-specific deaths and deaths from other causes were censored. The proportional hazard assumption for the covariates was tested by Schoenfeld residuals and by plotting the log of the negative log of the survival function versus the log of time.

The study was approved by the regional ethical review board at Lund.

\section{Results}

The numbers of AID patients are shown in Table 1 after the name of the disease and the first column shows the numbers of person-years at risk. Of the 33 AIDs analyzed, 21 had more than 3 cases of myelomas and these are shown in the Tables. For myeloma after any AID, including the ones not shown, the SIR was increased to 1.12, while the HR was 0.92 (not significant, Table 1). SIRs were significantly increased after ankylosing spondylitis (2.02) and systemic sclerosis (2.63). No SIR was significantly decreased. Only the HR after rheumatic fever (5.27) was significantly increased.

The data were analyzed according to the age at myeloma diagnosis (Table 2). Note that the number of patients followed for myeloma was the same as in Table 2. The overall risk of myeloma was increased only for those diagnosed before age 60 years (SIR 1.45); the significant SIRs were noted for ankylosing spondylitis (3.31), chronic rheumatic heart disease (2.79) and systemic lupus erythematosus (5.19). The HRs in young patients were increased after Graves/hyperthyroidism (2.48), rheumatic fever (21.17, but only one death) and systemic sclerosis (5.51). In myeloma patients diagnosed at age $60+$ years, only the risk for systemic sclerosis was increased (2.59). HRs were increased after polymyositis/ dermatomyositis (5.40) and rheumatic fever (4.60).

In Table 3 the data were analyzed in two periods, 1964 to 1990 and 1991 to 2008; the patient numbers are shown in the parentheses. The overall SIR was only 
Table 1 SIRs and HRs for myeloma after a specified Al disease

\begin{tabular}{|c|c|c|c|c|c|c|c|}
\hline Autoimmune disease (case numbers) & Pyrs & 0 & SIR & $95 \% \mathrm{Cl}$ & Deaths & HR & $95 \% \mathrm{Cl}$ \\
\hline Ankylosing spondylitis (6646) & 112824 & 16 & 2.02 & $1.15-3.28$ & 4 & 0.60 & $0.22-1.59$ \\
\hline Behcet disease (3874) & 63182 & 6 & 1.48 & $0.53-3.23$ & 3 & 0.64 & $0.21-1.98$ \\
\hline Chronic rheumatic heart disease (21027) & 166242 & 23 & 0.92 & $0.58-1.39$ & 9 & 0.93 & $0.48-1.79$ \\
\hline Crohn disease (25677) & 392264 & 15 & 0.82 & $0.46-1.36$ & 9 & 1.20 & $0.62-2.31$ \\
\hline Graves/hyperthyroidism (42020) & 541104 & 52 & 1.03 & $0.77-1.35$ & 29 & 0.88 & $0.61-1.27$ \\
\hline Hashimoto/hypothyroidism (13160) & 120705 & 15 & 1.14 & $0.64-1.89$ & 4 & 0.40 & $0.15-1.06$ \\
\hline Immune thrombocytopenic purpura (4324) & 44220 & 4 & 2.13 & $0.55-5.51$ & 2 & 0.57 & $0.14-2.30$ \\
\hline Multiple sclerosis (14616) & 185014 & 13 & 0.99 & $0.53-1.70$ & 8 & 1.25 & $0.62-2.49$ \\
\hline Myasthenia gravis (3044) & 32648 & 4 & 1.35 & $0.35-3.49$ & 3 & 1.85 & $0.60-5.74$ \\
\hline Pernicious anemia (11590) & 67096 & 13 & 1.01 & $0.54-1.74$ & 12 & 1.15 & $0.65-2.03$ \\
\hline Polymyalgia rheumatica (27534) & 253046 & 43 & 1.20 & $0.87-1.62$ & 27 & 1.05 & $0.72-1.53$ \\
\hline Polymyositis/dermatomyositis (2465) & 24041 & 4 & 1.80 & $0.47-4.65$ & 3 & 1.41 & $0.45-4.38$ \\
\hline Psoriasis (19777) & 275971 & 23 & 0.98 & $0.62-1.47$ & 11 & 0.75 & $0.41-1.35$ \\
\hline Rheumatic fever (4306) & 77388 & 8 & 1.34 & $0.57-2.65$ & 6 & 5.27 & $2.37-11.75$ \\
\hline Rheumatoid arthritis (72309) & 731954 & 81 & 0.88 & $0.70-1.09$ & 45 & 0.93 & $0.69-1.24$ \\
\hline Sarcoidosis (11571) & 177765 & 19 & 1.30 & $0.78-2.03$ & 11 & 1.05 & $0.58-1.90$ \\
\hline Sjögren syndrome (1957) & 16700 & 4 & 2.10 & $0.55-5.42$ & 1 & 0.30 & $0.04-2.13$ \\
\hline Systemic lupus erythematosus (7624) & 86627 & 11 & 1.71 & $0.85-3.07$ & 5 & 1.10 & $0.46-2.63$ \\
\hline Systemic sclerosis (7169) & 89997 & 19 & 2.63 & $1.58-4.11$ & 13 & 0.92 & $0.53-1.60$ \\
\hline Ulcerative colitis (33493) & 486704 & 38 & 1.36 & $0.96-1.87$ & 21 & 0.96 & $0.62-1.47$ \\
\hline Wegener granulomatosis (15833) & 115746 & 26 & 1.17 & $0.76-1.72$ & 6 & 0.77 & $0.47-1.26$ \\
\hline All (402462) & 4777665 & 457 & 1.12 & $1.02-1.23$ & 251 & 0.92 & $0.81-1.04$ \\
\hline
\end{tabular}

Bold type indicates that the $95 \% \mathrm{Cl}$ does not include 1.00 .

Abbreviations: Pyrs, person-years; O, observed; SIR, standardized incidence ratio; $\mathrm{Cl}$, confidence interval; $\mathrm{HR}$, hazard ratio.

increased when myeloma was diagnosed in years 1964 to 1990 (1.31), systemic sclerosis showing the only significant association (3.60). The overall HR was not changed for this period, but increased HRs for myeloma were noted after multiple sclerosis (4.02), rheumatic fever (5.06) and systemic lupus erythematosus (15.48). In period 1991-2008, the overall SIR was not increased and myeloma was increased only after ankylosing spondylitis (2.09). HRs for myeloma were increased in polymyositis/ dermatomyositis (6.44) and rheumatic fever (4.43) patients.

\section{Discussion}

Myeloma remains a fatal disease even though the relative survival in Sweden has increased from 19\% in 1964 to $39 \%$ in 2003 [22]. The improvements have been ascribed to more effective treatment modalities, which include melphalan-prednisone covering the present study period and interferon alpha since the late 1970s [19]. High-dose melphalan therapy and autologous stem-cell transplantation were introduced in Sweden in the late 1980 and thalidomide began to be used about a decade later
[19]. Thus, in the latter part of our follow-up period (1991-2008), many therapeutic innovations were in use, and the overall myeloma risk and survival were identical in AID patients and the population not hospitalized for AIDs. The risk of myeloma remained elevated for ankylosing spondylitis patients and was still of borderline significance for systemic sclerosis patients, although the SIR had decreased compared to the earlier part of the follow-up period (1964-1990). Risk of myeloma before age 60 years was increased in chronic rheumatic heart disease and systemic lupus patients.. Ankylosing spondylitis and systemic sclerosis were associated with myeloma in the earlier US study on male veterans [4]. In that study, myeloma risk was associated with a few other AIDs that were not associated with myeloma risk in our study, probably partly for statistical reasons: there were 4,641 cases of myeloma in the US study compared with 457 in the present study. Another reason may be the gender, as only males were included in the US study.

We have been unable to find previous publications documenting adverse (or beneficial) effects of AID for myeloma survival. The reasons for poorer survival in 
Table 2 SIRs and HRs for myeloma after a specified AI disease by age at cancer diagnosis

\begin{tabular}{|c|c|c|c|c|c|c|c|c|c|c|c|c|c|}
\hline \multirow[b]{2}{*}{ Autoimmune disease } & \multirow[b]{2}{*}{ Pyrs } & \multicolumn{6}{|c|}{$0<$ Age $<60$} & \multicolumn{6}{|c|}{ Age60 } \\
\hline & & 0 & SIR & $95 \% \mathrm{Cl}$ & Deaths & HR & $95 \% \mathrm{Cl}$ & 0 & SIR & $95 \% \mathrm{Cl}$ & Deaths & HR & $95 \% \mathrm{Cl}$ \\
\hline Ankylosing spondylitis & 112824 & 8 & 3.31 & $1.41-6.55$ & 3 & 1.00 & $0.32-3.11$ & 8 & 1.45 & $0.62-2.87$ & 1 & 0.29 & $0.04-2.01$ \\
\hline Behcet disease & 63182 & 2 & 1.99 & $0.19-7.32$ & 0 & & & 4 & 1.31 & $0.34-3.38$ & 3 & 1.05 & $0.34-3.24$ \\
\hline Chronic rheumatic heart disease & 166242 & 6 & 2.79 & $1.00-6.11$ & 4 & 1.25 & $0.47-3.33$ & 17 & 0.75 & $0.43-1.20$ & 5 & 0.82 & $0.34-1.96$ \\
\hline Crohn disease & 392264 & 5 & 0.89 & $0.28-2.09$ & 3 & 1.47 & $0.47-4.57$ & 10 & 0.79 & $0.38-1.46$ & 6 & 1.12 & $0.50-2.50$ \\
\hline Graves/hyperthyroidism & 541104 & 7 & 0.98 & $0.39-2.04$ & 5 & 2.48 & $1.03-5.98$ & 45 & 1.04 & $0.76-1.39$ & 24 & 0.80 & $0.53-1.19$ \\
\hline Hashimoto/hypothyroidism & 120705 & 1 & 0.85 & $0.00-4.87$ & 0 & & & 14 & 1.17 & $0.64-1.97$ & 4 & 0.44 & $0.16-1.16$ \\
\hline Immune thrombocytopenic purpura & 44220 & 0 & & & & & & 4 & 2.51 & $0.65-6.50$ & 2 & 0.57 & $0.14-2.27$ \\
\hline Multiple sclerosis & 185014 & 3 & 0.86 & $0.16-2.56$ & 0 & & & 10 & 1.04 & $0.49-1.92$ & 8 & 1.84 & $0.92-3.68$ \\
\hline Myasthenia gravis & 32648 & 1 & 2.60 & $0.00-14.91$ & 1 & 2.41 & $0.34-17.14$ & 3 & 1.16 & $0.22-3.45$ & 2 & 1.55 & $0.39-6.18$ \\
\hline Pernicious anemia & 67096 & 1 & 2.38 & $0.00-13.63$ & 1 & 0.49 & $3.06-3.48$ & 12 & 0.97 & $0.50-1.70$ & 11 & 1.30 & $0.72-2.35$ \\
\hline Polymyalgia rheumatica & 253046 & 5 & 1.93 & $0.61-4.55$ & 3 & 0.94 & $0.30-2.92$ & 38 & 1.14 & $0.81-1.57$ & 24 & 1.05 & $0.70-1.56$ \\
\hline Polymyositis/dermatomyositis & 24041 & 1 & 3.19 & $0.00-18.26$ & 0 & & & 3 & 1.57 & $0.30-4.65$ & 3 & 5.40 & $1.75-16.65$ \\
\hline Psoriasis & 27591 & 5 & 1.19 & $0.38-2.80$ & 1 & 0.43 & $0.06-3.06$ & 18 & $0.94-$ & $0.55-1.48$ & 10 & 0.80 & $0.43-1.49$ \\
\hline Rheumatic fever & 77388 & 1 & 0.76 & $0.00-4.35$ & 1 & 21.17 & $2.96-151.59$ & 7 & 1.50 & $0.60-3.11$ & 5 & 4.60 & $1.91-11.06$ \\
\hline Rheumatoid arthritis & 731954 & 8 & 0.90 & $0.39-1.79$ & 2 & 0.45 & $0.11-1.89$ & 73 & 0.88 & $0.69-1.10$ & 43 & 0.96 & $0.71-1.29$ \\
\hline Sarcoidosis & 177765 & 4 & 1.26 & $0.33-3.27$ & 2 & 1.19 & $0.30-4.78$ & 15 & 1.31 & $0.73-2.16$ & 9 & 1.07 & $0.55-2.05$ \\
\hline Sjögren syndrome & 16700 & 1 & 4.58 & $0.00-26.27$ & 0 & & & 3 & 1.78 & $0.33-5.26$ & 1 & 0.34 & $0.05-2.38$ \\
\hline Systemic lupus erythematosus & 86627 & 6 & 5.19 & $1.87-11.36$ & 3 & 1.42 & $0.46-4.41$ & 5 & 0.95 & $0.30-2.23$ & 2 & 0.86 & $0.22-3.45$ \\
\hline Systemic sclerosis & 89997 & 3 & 2.87 & $0.54-8.49$ & 3 & 5.51 & $1.75-17.29$ & 16 & 2.59 & $1.47-4.2$ & 10 & 0.80 & $0.43-1.49$ \\
\hline Ulcerative colitis & 486704 & 11 & 1.50 & $0.75-2.70$ & 6 & 0.85 & $0.38-1.89$ & 27 & 1.31 & $0.86-1.90$ & 15 & 1.05 & $0.63-1.74$ \\
\hline Wegener granulomatosis & 115746 & 2 & 3.91 & $0.37-14.36$ & 2 & 1.91 & $0.48-7.68$ & 24 & 1.11 & $0.71-1.65$ & 14 & 0.71 & $0.42-1.20$ \\
\hline All & 4777665 & 84 & 1.45 & $1.16-1.80$ & 40 & 0.96 & $0.70-1.32$ & 373 & 1.07 & $0.96-1.18$ & 211 & 0.92 & $0.80-1.06$ \\
\hline
\end{tabular}

Bold type indicates that the $95 \% \mathrm{Cl}$ does not include 1.00 .

Abbreviations: Pyrs, person-years; O, observed; SIR, standardized incidence ratio; $\mathrm{Cl}$, confidence interval; HR, hazard ratio. 
Table 3 SIRs and HRs for myeloma after a specified Al disease by diagnostic period of cancer

\begin{tabular}{|c|c|c|c|c|c|c|c|c|c|c|c|c|c|c|}
\hline \multirow{2}{*}{$\begin{array}{l}\text { Autoimmune disease } \\
\text { (case numbers in the two periods) }\end{array}$} & \multicolumn{7}{|c|}{ 1964-1990 } & \multicolumn{7}{|c|}{ 1991-2008 } \\
\hline & Pyrs & 0 & SIR & $95 \% \mathrm{Cl}$ & Deaths & HR & $95 \% \mathrm{Cl}$ & Pyrs & 0 & SIR & $95 \% \mathrm{Cl}$ & Deaths & HR & $95 \% \mathrm{Cl}$ \\
\hline Ankylosing spondylitis (4692/1954) & 39322 & 3 & 1.73 & $0.33-5.12$ & 1 & 3.60 & $0.50-25.72$ & 73502 & 13 & 2.09 & $1.11-3.59$ & 2 & 0.40 & $0.10-1.59$ \\
\hline Behcet disease (3635/239) & 28513 & 3 & 2.14 & $0.40-6.35$ & 3 & 1.38 & $0.45-4.29$ & 34669 & 3 & 1.12 & $0.21-3.33$ & 0 & & \\
\hline Chronic rheumatic heart disease (17015/4012) & 85701 & 13 & 1.16 & $0.62-1.99$ & 6 & 1.55 & $0.70-3.46$ & 80541 & 10 & 0.73 & $0.35-1.35$ & 2 & 0.43 & $0.11-1.73$ \\
\hline Crohn disease (12733/12944) & 110614 & 3 & 1.01 & $0.19-3.00$ & 1 & 1.19 & $0.17-8.43$ & 281650 & 12 & 0.78 & $0.40-1.37$ & 6 & 1.22 & $0.55-2.71$ \\
\hline Graves/hyperthyroidism (26633/15387) & 203693 & 22 & 1.32 & $0.82-2.00$ & 8 & 0.61 & $0.31-1.23$ & 337411 & 30 & 0.89 & $0.60-1.27$ & 15 & 1.17 & $0.71-1.95$ \\
\hline Hashimoto/hypothyroidism (8375/4785) & 43501 & 8 & 1.88 & $0.80-3.72$ & 3 & 1.16 & $0.37-3.59$ & 77204 & 7 & 0.79 & $0.31-1.64$ & 0 & & \\
\hline Immune thrombocytopenic purpura $(965 / 3359)$ & 8640 & 1 & 4.44 & $0.00-25.4$ & 1 & 0.53 & $0.07-3.73$ & 355800 & 3 & 1.81 & $0.34-5.37$ & 1 & 0.61 & $0.09-4.35$ \\
\hline Multiple sclerosis (8782/5834) & 67706 & 4 & 1.03 & $0.27-2.67$ & 2 & 4.02 & $1.01-16.01$ & 117308 & 9 & 0.97 & $0.44-1.86$ & 5 & 1.14 & $0.47-2.73$ \\
\hline Myasthenia gravis (1551/1493) & 10430 & 2 & 2.91 & $0.27-10.7$ & 0 & & & 22218 & 2 & 0.88 & $0.08-3.23$ & 2 & 1.92 & $0.48-7.67$ \\
\hline Pernicious anemia (9687/1903) & 32746 & 5 & 0.83 & $0.26-1.96$ & 3 & 0.72 & $0.23-2.22$ & 34350 & 8 & 1.17 & $0.50-2.32$ & 7 & 1.37 & $0.66-2.88$ \\
\hline Polymyalgia rheumatica (13278/14256) & 72444 & 10 & 1.59 & $0.76-2.94$ & 5 & 1.35 & -0.563 .24 & 180602 & 33 & 1.12 & $0.77-1.57$ & 18 & 0.92 & $0.581-1.46$ \\
\hline Polymyositis/dermatomyositis (1295/1170) & 8310 & 1 & 1.57 & $0.00-9.00$ & 0 & & & 15731 & 3 & 1.89 & $0.36-5.59$ & 3 & 6.44 & $2.08-20.0$ \\
\hline Psoriasis (14068/5709) & 112458 & 11 & 1.51 & $0.75-2.71$ & 5 & 0.78 & $0.32-1.88$ & 163513 & 12 & 0.74 & $0.38-1.30$ & 2 & 0.31 & $0.08-1.24$ \\
\hline Rheumatic fever (3888/418) & 34274 & 4 & 2.05 & $0.53-5.30$ & 2 & 5.06 & $1.26-20.28$ & 43114 & 4 & 0.99 & $0.26-2.57$ & 3 & 4.43 & $1.43-13.7$ \\
\hline Rheumatoid arthritis (49139/23170) & 304697 & 35 & 1.02 & $0.71-1.41$ & 16 & 0.81 & $0.49-1.32$ & 427257 & 46 & 0.80 & $0.58-06$ & 25 & 1.19 & $0.80-1.77$ \\
\hline Sarcoidosis (7856/3715) & 69124 & 9 & 2.17 & $0.98-4.14$ & 6 & 1.31 & $0.59-2.93$ & 108641 & 10 & 0.95 & $0.45-1.76$ & 3 & 0.75 & $0.24-2.32$ \\
\hline Sjögren syndrome (716/1241) & 3386 & 1 & 3.10 & $0.00-17.7$ & 1 & 0.87 & $0.12-6.15$ & 13314 & 3 & 1.89 & $0.36-5.60$ & 0 & & \\
\hline Systemic lupus erythematosus $(4717 / 2907)$ & 31854 & 4 & 1.93 & $0.50-4.99$ & 4 & 15.48 & $5.79-41.42$ & 54773 & 7 & 1.60 & $0.64-3.32$ & 1 & 0.25 & $0.04-1.80$ \\
\hline Systemic sclerosis $(5795 / 1374)$ & 36494 & 10 & 3.60 & $1.71-6.64$ & 7 & 0.91 & $0.43-1.93$ & 53503 & 9 & 2.02 & $0.92-3.85$ & 5 & 1.35 & $0.56-3.25$ \\
\hline Ulcerative colitis (17071/16422) & 136018 & 5 & 0.95 & $0.30-2.23$ & 1 & 0.27 & $0.04-1.95$ & 350686 & 33 & 1.45 & $1.00-2.04$ & 19 & 1.46 & $0.93-2.29$ \\
\hline Wegener granulomatosis $(14233 / 1600)$ & 61898 & 14 & 1.20 & $0.65-2.02$ & 3 & 0.32 & $0.10-1.00$ & 53848 & 12 & 1.14 & $0.59-2.00$ & 10 & 1.22 & $0.66-2.28$ \\
\hline All $(253449 / 149013) 1696388$ & 1696388 & 171 & 1.31 & $1.12-1.52$ & 78 & 0.88 & $0.70-1.10$ & 3081277 & 286 & 1.04 & $0.92-1.16$ & 137 & 0.99 & $0.99-1.17$ \\
\hline
\end{tabular}

Bold type indicates that the $95 \% \mathrm{Cl}$ does not include 1.00 .

Abbreviations: Pyrs, person-years; O, observed; SIR, standardized incidence ratio; $\mathrm{Cl}$, confidence interval; $\mathrm{HR}$, hazard ratio. 
AID patients could be the weak overall physical condition or non-tolerance of therapy, both of which have been described for various cancers [23-25]. In the Swedish study comparing periodic effects on myeloma survival, the most favorable trends were seen for the young patients who also received the most aggressive therapies and were candidates for bone marrow transplantation [19]. The present data showed no overall influence of AID on survival and the null results remained when myeloma diagnostic age groups or periods were considered. However, among individual AIDs, poor survival was observed for rheumatic fever, irrespective of diagnostic age or period. Interestingly, rheumatic fever has previously been shown as a risk factor for myeloma which, however, was not evident in the present study [12]. Rheumatic fever is caused by streptococcal infection usually in childhood. The resulting carditis may develop to congestive heart diseases and this was the likely co-morbidity affecting survival; most of the affected rheumatoid fever patients were $60+$ years in the present study. Other AIDs that appeared to worsen survival in myeloma were polymyositis/dermatomyositis (only age 60+ and period 1991 to 2008) and multiple sclerosis and systemic lupus erythematosus (only period 1964 to 1990), all quite devastating AIDs and likely to act as co-morbidities.

The present paper is a continuation in a series of studies on cancers following AIDs, including so far digestive tract, lung cancers and skin cancers [6,26-28]. Although there is no general pattern of certain AIDs leading to increases of all or most cancers, systemic sclerosis, leading to the highest SIR of myeloma, causes also significant increases in esophageal cancer, lung adenocarcinoma and squamous cell carcinoma and skin squamous cell carcinoma. Changes in survival (HR) are not as common as changes in SIR, even in cancers previously studied, at least in part because case numbers are less. We have not previously observed increases in HR of cancer after rheumatic fever.

In conclusion, the present data showed an increase in myeloma SIR after two AIDs (ankylosing spondylitis and systemic sclerosis) and HR after rheumatic fever. The overall myeloma risk after any AID was no longer increased in the latter follow-up period of 1991 through 2008.

\section{Competing interests}

The authors declare that they have no competing interests.

\section{Authors' contributions}

(1) the conception and design of the study, or acquisition of data, or analysis and interpretation of data: all authors, (2) drafting the article or revising it critically for important intellectual content: $\mathrm{KH}, \mathrm{AF}, \mathrm{KS}$, (3) final approval of the version to be submitted: all authors. All authors read and approved the final manuscript.

\section{Acknowledgments}

This study was supported by ALF funding from Region Skane, a grant from the Swedish Research Council, and Deutsche Krebshilfe. The funding sources had no influence on the study.

\section{Author details}

'Division of Molecular Genetic Epidemiology, German Cancer Research Center (DKFZ), Im Neuenheimer Feld 580, Heidelberg D-69120, Germany. ${ }^{2}$ Center for Primary Health Care Research, Lund University, Malmö 20502 , Sweden. ${ }^{3}$ College of Lab Medicine, Hebei North University, Zhangjiakou 075800, China. ${ }^{4}$ Stanford Prevention Research Center, Stanford University School of Medicine, Stanford, CA 94305-5705, USA.

Received: 3 September 2012 Accepted: 26 September 2012

Published: 2 October 2012

\section{References}

1. Forabosco P, Bouzigon E, Ng MY, Hermanowski J, Fisher SA, Criswell LA, Lewis CM: Meta-analysis of genome-wide linkage studies across autoimmune diseases. Eur J Hum Genet 2009, 17:236-243.

2. Zhernakova A, van Diemen CC, Wijmenga C: Detecting shared pathogenesis from the shared genetics of immune-related diseases. Nat Rev Genet 2009, 10:43-55.

3. Goldin LR, Landgren O: Autoimmunity and lymphomagenesis. Int I Cancer 2009, 124:1497-1502.

4. Brown LM, Gridley G, Check D, Landgren O: Risk of multiple myeloma and monoclonal gammopathy of undetermined significance among white and black male United States veterans with prior autoimmune, infectious, inflammatory, and allergic disorders. Blood 2008, 111:3388-3394.

5. Landgren AM, Landgren O, Gridley G, Dores GM, Linet MS, Morton LM Autoimmune disease and subsequent risk of developing alimentary tract cancers among 4.5 million US male veterans. Cancer 2011, 117:1163-1171.

6. Hemminki K, Liu X, Ji J, Sundquist J, Sundquist K: Autoimmune disease and subsequent digestive tract cancer by histology. Ann Oncol 2012, in press.

7. Vajdic CM, van Leeuwen MT: Cancer incidence and risk factors after solid organ transplantation. Int I Cancer 2009, 125:1747-1754.

8. Rothwell PM, Fowkes FG, Belch JF, Ogawa H, Warlow CP, Meade TW: Effect of daily aspirin on long-term risk of death due to cancer: analysis of individual patient data from randomised trials. Lancet 2011, 377:31-41.

9. Anderson KC, Carrasco RD: Pathogenesis of myeloma. Annu Rev Pathol 2011, 6:249-274

10. Morgan GJ, Walker BA, Davies FE: The genetic architecture of multiple myeloma. Nat Rev Cancer 2012, 12:335-348.

11. Kyle RA, Rajkumar SV: Epidemiology of the plasma-cell disorders. Best Pract Res Clin Haematol 2007, 20:637-664.

12. Koepsell TD, Daling JR, Weiss NS, Taylor JW, Olshan AF, Lyon JL, Swanson $\mathrm{GM}$, Child M: Antigenic stimulation and the occurrence of multiple myeloma. Am J Epidemiol 1987, 126:1051-1062.

13. Landgren $\mathrm{O}$, Linet MS, McMaster ML, Gridley G, Hemminki K, Goldin LR: Familial characteristics of autoimmune and hematologic disorders in 8,406 multiple myeloma patients: A population-based case-control study. Int J Cancer 2006, 118:3095-3098.

14. Hemminki K, Li X, Sundquist J, Sundquist K: Cancer risks in Crohn disease patients. Ann Oncol 2009, 20:574-580

15. Ji J, Shu X, Li X, Sundquist K, Sundquist J, Hemminki K: Cancer risk in hospitalized sarcoidosis patients: a follow-up study in Sweden. Ann Oncol 2009, 20:1121-1126.

16. Ji J, Liu X, Sundquist K, Sundquist J: Survival of cancer in patients with rheumatoid arthritis: a follow-up study in Sweden of patients hospitalized with rheumatoid arthritis 1 year before diagnosis of cancer. Rheumatology (Oxford) 2011, 50:1513-1518.

17. Shu X, Ji J, Sundquist J, Sundquist K, Hemminki K: Survival in cancer patients hospitalized for psoriasis: a population-based cohort study in Sweden. Br J Dermatol 2011, 165:129-136

18. Shu X, Ji J, Sundquist J, Sundquist K, Hemminki K: Survival in cancer patients hospitalized for inflammatory bowel disease in Sweden. Inflamm Bowel Dis 2011, 17:816-822.

19. Kristinsson SY, Landgren O, Dickman PW, Derolf AR, Bjorkholm M: Patterns of survival in multiple myeloma: a population-based study of patients diagnosed in Sweden from 1973 to 2003. J Clin Oncol 2007, 25:1993-1999. 
20. Hemminki K, Li X, Sundquist K, Sundquist J: Familial risks for chronic obstructive pulmonary disease among siblings based on hospitalizations in Sweden. J Epidemiol Community Health 2008, 62:398-401.

21. Hemminki K, Li X, Sundquist K, Sundquist J: Familial risks for asthma among twins and other siblings based on hospitalizations in Sweden. Clin Exp Allergy 2007, 37:1320-1325.

22. Storm HH, Klint A, Tryggvadottir L, Gislum M, Engholm G, Bray F, Hakulinen $\mathrm{T}$ : Trends in the survival of patients diagnosed with malignant neoplasms of lymphoid, haematopoietic, and related tissue in the Nordic countries 1964-2003 followed up to the end of 2006. Acta Oncol 2010, 49:694-712.

23. Extermann M: Interaction between comorbidity and cancer. Cancer Control 2007. 14:13-22.

24. Riihimaki M, Thomsen H, Brandt A, Sundquist J, Hemminki K: What do prostate cancer patients die of? Oncologist 2011, 16:175-181.

25. Riihimaki M, Thomsen H, Brandt A, Sundquist J, Hemminki K: Death causes in breast cancer patients. Ann Oncol 2012, 23:604-610

26. Hemminki K, Liu X, Ji J, Sundquist J, Sundquist K: Effect of autoimmune diseases on mortality and survival in subsequent digestive tract cancers. Ann Oncol 2012, in press.

27. Hemminki K, Liu X, Ji J, Sundquist J, Sundquist K: Effect of autoimmune diseases on risk and survival in histology-specific lung cancer. Eur Respir $」$ 2012, in press.

28. Hemminki K, Liu X, Ji J, Sundquist J, Sundquist K: Kaposi sarcoma and Merkel cell carcinoma after autoimmune disease. Int J Cancer 2012, 131:E326-E328.

doi:10.1186/1756-8722-5-59

Cite this article as: Hemminki et al:: Effect of autoimmune diseases on incidence and survival in subsequent multiple myeloma. Journal of Hematology \& Oncology 2012 5:59.

\section{Submit your next manuscript to BioMed Central and take full advantage of:}

- Convenient online submission

- Thorough peer review

- No space constraints or color figure charges

- Immediate publication on acceptance

- Inclusion in PubMed, CAS, Scopus and Google Scholar

- Research which is freely available for redistribution 